\title{
Hiatus resolution in Persian: The case of [t]-epenthesis
}

\author{
Amir Ghorbanpour \\ Tarbiat Modares University, Tehran \\ amir.ghorbanpour@modares.ac.ir
}

\author{
Aliyeh K. Z. Kambuziya \\ Tarbiat Modares University, Tehran \\ akord@modares.ac.ir
}

\section{Mohammad Dabir-Moghaddam \\ Allameh Tabatabaei University, Tehran \\ dabirmoghaddam@atu.ac.ir \\ Ferdows Agha-Golzadeh \\ Tarbiat Modares University, Tehran \\ aghagolz@modares.ac.ir}

\begin{abstract}
This paper analyses the case of hiatus resolution in the /e-i/ and /e-a/ environments in tetrasyllabic words in Persian, within an Optimality-theoretic framework. Hiatus is avoided in Persian by the insertion of an epenthetic consonant which varies considerably depending on the morpho-phonemic environment in which hiatus occurs. It is argued that the insertion of [t] as a hiatus-resolving consonant in Persian is historically driven. We follow Naderi and van Oostendorp (2011) in assuming that the hiatus-resolving [t] is actually a latent segment at the end of bases ending in /e/ - in some words as a relic from the Middle (Pahlavi) Persian and in others as a matter of analogy - surfacing only in certain morpho-phonemic contexts. We argue that the two hiatus-resolving consonants realised in an /e-i/ environment in Persian - i.e., the phonetically-driven [?] and the historically-driven [t] - are in complementary distribution depending on the grammatical class of the output word. Within an OT framework, we aimed to achieve a unified explanation and a set order of constraints active for hiatus resolution in the /e-i/ and /e-a/ environments.
\end{abstract}

Keywords: phonology; vowel hiatus; consonant epenthesis; Optimality theory; Persian

\section{Introduction ${ }^{1}$}

Vowel hiatus is generally avoided in Persian by the insertion of an epenthetic consonant. This epenthetic consonant varies considerably depending

${ }^{1}$ This paper is taken from the first author's doctoral dissertation under the supervision of Dr. Aliyeh K. Z. Kambuziya. 
on the morpho-phonemic environment in which the hiatus occurs. In fact, this variation is to the extent that it is generally argued that there are up to nine epenthetic consonants in Persian (Sadeghi 2002; Bijankhan 2005, 12-15; Kambuziya 2007, 277-306; inter alia). One of the phonemic environments in which consonant epenthesis occurs is an /e-i/ hiatus; that is, a case where a suffix $/-\mathrm{i} /$ is attached to a base ending in $/ \mathrm{e} /$. There are two derivational suffixes $/-\mathrm{i} /$ in Persian. In fact, there is also a third, inflectional /-i/ (the indefinite marker) which we will not focus on here - as it applies at the level of syntax and also behaves differently in terms of stress assignment. Of the two derivational suffixes $/-\mathrm{i} /$, one is an adjectiviser $/-\mathrm{i} /$ which is attached to (mostly noun) bases to make adjectives; and the other, a nominaliser /-i/ added to (mostly adjective) bases to make nouns. Hence the two suffixes are phonologically the same, but behave differently in terms of the morpho-grammatical functions they have. Examples of the two suffixes are given below:

(1) Adjectiviser /-i/

/baran/ 'rain' (n.) + /-i/ $\rightarrow$ [barani] 'rainy' (adj.)

(2) Nominaliser $/-\mathrm{i} /$

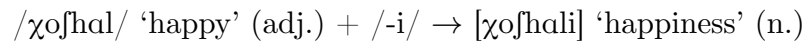

However, these same suffixes when added to bases ending in /e/ create a hiatus of /e-i/ which is resolved by the insertion of an epenthetic consonant. This epenthetic consonant in the case of an adjective-forming derivation is a glottal stop [?]. However, the nominaliser /-i/ when suffixed to bases ending in /e/ gives rise to the emergence of a different epenthetic consonant, i.e., [f], to resolve this /e-i/ hiatus. This difference in hiatus resolution is shown in the following examples where the same two suffixes in (1) and (2) above are added to bases ending in the vowel /e/:

(3) Adjectiviser /-i / added to bases ending in /e/

$$
\begin{array}{ll}
\text { /ceraje/ 'rent' (n.) +/-i } / \text { [ceraje?i] 'rental' (adj.) } \\
\text { /setare/ 'star' (n.) }+/ \text {-i/ } & \rightarrow \text { [setare?i] 'starlike' (adj.) } \\
\text { /firuze/ 'turquoise' (n.) }+/ \text {-i/ } & \rightarrow \text { [firuze?i] 'turquoise (colour)' (adj.) }
\end{array}
$$

(4) Nominaliser /-i/ added to bases ending in /e/

/forosne/ 'hungry' (adj.) + /-i/ $\rightarrow$ [gorosnefi] 'hunger' (n.)

/divane/ 'insane' (adj.) $+/-\mathrm{i} / \rightarrow$ [divanefi] 'insanity' (n.)

/afsorde/ 'depressed' (adj.) $+/-\mathrm{i} / \rightarrow$ [?afsordeji $]^{2}$ 'depression' (n.) 
The insertion of a glottal stop [?] in an adjective-forming derivation makes sense phonetically, since it is the unmarked epenthetic consonant in many languages (see Kenstowicz 1994, 97; Lombardi 2001b; inter alia), including a number of other phonetic environments in Persian; e.g., in the beginning position of the vowel-initial words to provide an obligatory onset in their phonetic realisations (as already evident in the phonetic realisation of the last example in (4) above: [?afsordefi] 'depression'). The insertion of [f], however, has more to do with a historical development of Persian - as we will see below -, rather than being phonetically justified.

In this paper, we shall argue that the two epenthetic consonants discussed above, i.e., the phonetically-driven [?] and the historically-driven $[\mathrm{f}]$, are in fact in complementary distribution depending on the grammatical class of the output word. Regarding the insertion of [f] in a nounforming derivation - and in an /e-a/ environment as discussed later on - we will follow Naderi and van Oostendorp (2011) in assuming that the hiatus-resolving $[\mathrm{f}]$ is actually a latent segment rather than being a truly epenthetic consonant; differentiating this, however, from the adjectiveforming derivation in which a glottal stop [?] is epenthesised. Adopting an Optimality-theoretic framework, we aim to achieve a unified explanation and a set order of conflicting constraints which are active for hiatus resolution in the /e-i/ - and the closely related /e-a/ - environment.

\section{Background}

\subsection{Epenthetic consonants in Persian}

As briefly stated above, the epenthetic consonants in Persian vary considerably depending on the environment in which the hiatus occurs. Sadeghi (2002) in a detailed discussion of vowel hiatus and epenthetic consonants in Persian, divides the epenthetic consonants of the language into two main groups; the first are the purely phonetic epenthetic consonants such as $[\mathrm{h}]$, $[\mathrm{P}],[\mathrm{j}]$ and $[\mathrm{w}]$; and the second group are those which are epenthesised in specific morpho-phonetic contexts. He mentions $[\mathrm{f}],[\mathrm{j}],[\mathrm{t}],[\mathrm{d}],[\mathrm{b}]$ and $[v]$ as instances of the epenthetic consonants of the second group. Sadeghi (2002) also discusses some historical considerations surrounding the nature

${ }^{2}$ In their phonetic realisations, all Persian syllables are considered to have an onset consonant. In cases where there is no onset in the underlying form, a glottal stop [?] is inserted. This is argued to hold true at least for the formal pronunciation of words in isolation. 
of the morpho-phonetic epenthetic consonants including $[f]$, which we will get back to shortly in the following section.

Bijankhan (2005) in a discussion on hiatus resolution in Persian argues that the question as to what consonant is inserted between the two adjacent vowels depends largely on the syntactic category of the main morpheme - i.e., the root (ibid., 14). He points out that in all cases of morpheme-boundary epenthesis, the final vowel in the first morpheme and the beginning vowel of the second morpheme create a hiatus which is then resolved by the insertion of a consonant so that the phonetic realisation of the words accord with the syllabic structure of Persian: that every syllable needs to start with a consonant (ibid., 15). He maintains that it is not possible to define a single morpho-phonological rule to cover all cases of consonant epenthesis without taking into account the syntactic category of the root (ibid.).

Kambuziya (2007, 277-306) also addresses the different types of epenthetic consonants in Persian under separate sections as "glottal stop epenthesis", "glide epenthesis", and "floating segments". When discussing floating segments, she argues that in some cases when certain vowel-final roots in Persian are placed adjacent to another vowel, to resolve hiatus, a consonant is inserted whose features do not match the features of the adjacent vowels. Referring to some historical facts concerning the existence of segments $[f]$ and $[j]$ in the final position of these groups of words at an earlier stage, she postulates that these consonants can best be regarded as floating segments in present-day Persian surfacing only in certain derivations (ibid., 296-303).

Naderi and van Oostendorp (2011) in a study of the number of epenthetic consonants in Persian argue that it is possible to reduce this number to three, i.e., the glottal stop [?] and the two glides [j] and [w]. They analyse the glottal stop [?] as the emergence of the unmarked, and assert that glottal stop is the pure phonological, syllabification-driven epenthetic consonant in Persian $(2011,153)$. They further argue that [f], and also [j] (before the Ezafe-marker), can be better analysed as "latent segments" which have segmental features but lack a root node. We shall take a closer look at this assumption about the hiatus-resolving [f] in the following section, and in section 4 when discussing $[\mathrm{f}]$-epenthesis in noun-forming derivations (section 4.1.2). 


\section{2. [t] as an epenthetic consonant?}

Assuming [f] as an epenthetic consonant can be problematic for a number of reasons. First of all, as Naderi and van Oostendorp (2011, 160) observe, [f] is a highly marked consonant in the hierarchy of place markedness (Prince \& Smolensky 2004) given in (5), and hence highly improbable to occur as an epenthetic consonant.

(5) Coronal Unmarkedness (Prince \& Smolensky 2004, 213)

Do not have a place of articulation other than coronal.

${ }^{*} \mathrm{LAB},{ }^{*} \mathrm{DOR} \gg{ }^{*} \mathrm{COR}$

Furthermore, the occurrence of [f] as a hiatus-resolving segment is - as we shall see below - "morphologically restricted, so there should be a morphophonological process which enforces its emergence and not a purely phonological one" (Naderi \& van Oostendorp 2011, 160).

The morpho-phonological contexts in which [f]-epenthesis generally occurs are limited to the three cases of suffixation sketched below:

(6) Nominaliser $/-\mathrm{i} /$ added to a base ending in /e/

/forosne/ 'hungry' (adj.) + /-i/ $\rightarrow$ [gorosnefi] 'hunger' (n.)

(7) Pluraliser /-an/ added to a base ending in /e/

/setare/ 'star' (n.) + /-an/ $\rightarrow$ [setaregan] $]^{3}$ 'stars' (n.)

(8) Adverbialiser /-ane/ added to a base ending in /e/

/batffe/ 'child' (n.) + /-ane/ $\rightarrow$ [batffegane] 'childishly' (adv.)

That means: phonetically, [f]-epenthesis is limited to the /e-i/ and /e-a/ environments; and morphologically, it is limited to the three types of suffixation listed above.

Before moving on to the discussion of the historical drive for [f]epenthesis, however, a few points should be clarified about the suffixations sketched above in (6) to (8). Given the fact that the emergence of [f] is limited to these three types of suffixation, it would be tempting to assume that the epenthetic consonant [f] may actually belong to the respective suffixes rather than being inserted or belonging to the root words as a latent segment; that is, to argue that $[\mathrm{f}]$, as part of the suffixes realised as allomorphs

${ }^{3}$ In this paper, the palatal stops $/ \mathrm{J} /$ and $/ \mathrm{c} /$ are taken to be underlying phonemes in the Persian sound system, only occurring as allophones $[\mathrm{g}]$ and $[\mathrm{k}]$ before back vowels in their phonetic realisations. 
[-fi], [-fan] and [-fane], respectively, surfaces only when these suffixes are added to bases ending in a vowel, in order to avoid the resulting hiatus. This assumption is ruled out, however, since the same suffixes when added to bases ending in a different vowel (other than $/ \mathrm{e} /$ ), do not trigger the emergence of $[\mathrm{f}]$ to resolve the hiatus; rather, in such cases it is the glottal stop [?] or one of the glides - [j] or [w] - which is epenthesised/formed to resolve the hiatus. This can be seen in the following groups of examples in (9) to (11), where the same suffixes are added to bases ending in a different vowel:

(9) Nominaliser $/-\mathrm{i} /$ added to bases ending in $/ \mathrm{a} /$ or $/ \mathrm{u} /$

$$
\begin{aligned}
& \text { /nabina/ 'blind' (adj.) + /-i/ } \rightarrow \text { [na.bi.na.Pi] 'blindness' (n.) } \\
& \text { /tavana/ 'capable' (adj.) }+/ \text {-i/ } \rightarrow \text { [ta.va.na.Pi] 'capability' (n.) } \\
& \text { /rahnama/ 'guide' (n.) +/-i/ } \rightarrow \text { [rah.na.ma.Pi] 'guidance' (n.) } \\
& / \text { Saciba/ 'patient' }(\text { adj. })+/-\mathrm{i} / \rightarrow \text { [ } \text { a.ci.ba.?i] 'patience' (n.) } \\
& \text { /tond } \chi \mathrm{u} / \text { 'irascible' (adj.) }+/-\mathrm{i} / \rightarrow \text { [tond. } \chi \mathrm{u} . \mathrm{Pi} \text { ' 'irascibility' (n.) }
\end{aligned}
$$

(10) Pluraliser /-an/ added to bases ending in / $\mathrm{u} /$ (Kambuziya et al. 2017, 388)

$$
\begin{array}{ll}
\text { /ahu/ 'deer' (n.) + /-an/ } & \rightarrow \text { [3a.ho.wan] 'deers' } \\
\text { /abru/ 'eyebrow' (n.) +/-an/ } & \rightarrow \text { [?ab.ro.wan] 'eyebrows' } \\
\text { /bazu/ 'arm' (n.) }+/ \text {-an/ } & \rightarrow \text { [ba.zo.wan] 'arms' } \\
\text { /banu/ 'lady' (n.) }+/ \text {-an/ } & \rightarrow \text { [ba.no.wan] 'ladies' } \\
\text { /fisu/ 'hair' (n.) }+/ \text {-an/ } & \rightarrow \text { [fi.so.wan] 'hair' }
\end{array}
$$

(11) Adverbialiser /-ane/ added to bases ending in $/ \mathrm{i} /$ or $/ \mathrm{u} /$

$$
\begin{aligned}
& \text { /muzi/ 'insidious' (adj.) +/-ane/ } \rightarrow \text { [mu.zi.ja.ne] 'insidiously' (adv.) } \\
& \text { /nafi/ 'awkward' (adj.) +/-ane/ } \rightarrow \text { [na.fi.ja.ne] 'awkwardly' (adv.) } \\
& \text { /maxfi/ 'secret' (adj.) +/-ane/ } \rightarrow \text { [max.fi.ja.ne] 'secretly' (adv.) } \\
& \text { /dzadu/ 'magic' (n.) +/-ane/ } \rightarrow \text { [dza.do.wa.ne] 'magically' (adv.) }
\end{aligned}
$$

In the examples in (9), the nominaliser /-i/ is suffixed to bases ending in vowels $/ \mathrm{a} /$ and $/ \mathrm{u} /$, and this has given rise to the insertion of a glottal stop [?] to resolve the resulting hiatus. In the examples in (10) the plural suffix $/-a n /$ is added to noun bases ending in $/ \mathrm{u} /$, triggering the epenthesis of the corresponding back glide [w] between the two vowels to avoid hiatus, and this back glide insertion generally causes the vowel $/ \mathrm{u} /$ to change (shorten) into [o] (Kambuziya et al. 2017, 388). And lastly, in the examples in (11) the

${ }^{4}$ These nouns are alternatively pronounced with a glide [j], instead of the glottal stop [?] - especially in connected causal speech -, as a result of assimilation to the following vowel [i]; e.g., [na.bi.na.ji], [ta.va.na.ji], etc. 
adverbialiser /-ane/ is suffixed to bases ending in /i/ and / $\mathrm{u}$, respectively, again triggering the epenthesis of the corresponding glides - i.e., the front glide [j] after / i/ (for the first three examples) and the back glide [w] after $/ \mathrm{u} /$ (the fourth example). As can be seen, in none of these cases [f] is epenthesised to resolve the resulting hiatus; and this hence rules out the assumption that [f] could actually be part of the three suffixes which are realised as allomorphs [-fi], [-fan] and [-fane], repectively, when suffixed to bases ending in vowels. In fact, all the cases of hiatus resolution observed in the examples in (9) to (11) - i.e., the epenthesis of [?] or the glides [j] or $[\mathrm{w}]$ - are phonetically justified, unlike the occurrence of $[\mathrm{f}]$ - in (6) to (8) - which is a highly marked consonant and hence very improbable to occur as an epenthetic consonant.

The emergence of $[\mathrm{f}]$ in contemporary Persian as a hiatus-resolving consonant in a limited set of morpho-phonemic contexts relates back to a historical development of the language. The point is that at an earlier stage of the language - in Middle (Pahlavi) Persian - nearly all the words ending in /e/ today, had the consonant [f] as their ending (Sadeghi 2002); for example, the word /bande/ 'servant' was pronounced [bandaf] in Middle Persian (ibid.). This consonant has gradually been deleted from the end position of such words and in their today's realisations these words are not pronounced with a $[\mathrm{f}]$ at the end. However, unlike the simple singular form of the words which have lost their [f] at the end position, in cases where this sound had been used in the middle of the word - in plural suffixation or in noun-forming derivation - there has been no deletion and the derived forms like [bandafih] 'servitude' and [bandagan] 'servants' continued to be pronounced with that [f] (Sadeghi 2002). However, this fact is concerned with a non-exhaustive set of words which end in /e/ in their present-day pronunciation. What is happening today is actually a matter of analogy: Persian speakers seem to assume by analogy that [f] is latently present in any word that ends in /e/ in Modern Persian and do insert a [f] in their word-forming practices in specific morpho-phonemic contexts.

As Sadeghi (2002) observes, the use of [f] in these specific contexts is clearly analogical and it even encompasses Arabic loanwords as well, as seen in the following examples:

(12) Nominaliser /-i / added to bases of Arabic origin ending in /e/

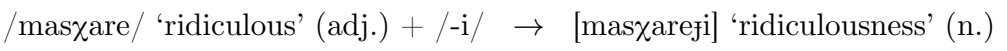

/talabe/ 'student' (n.) + /-i/ $\rightarrow$ [talabeji] 'studentship' (n.)

/hamele/ 'pregnant' (adj.) $+/-\mathrm{i} / \rightarrow$ [hamelefi] 'pregnancy' (n.) 
We thus assume this final [f] to be a latent segment in all words ending in /e/ in Modern Persian, surfacing only in a limited set of morpho-phonemic contexts as listed in (6) to (8) above. We follow Naderi and van Oostendorp (2011) in adopting Zoll's theory of subsegmental representation of latent segments. Zoll $(2001,47)$ suggests that "latent segments can be seen as a species of floating features, distinguished from full segments by the absence of a root node". She argues in favour of representing floating features and latent segments uniformly as subsegments, distinguished from segmental units by the fact that "segments are immediately syllabifiable while subsegments require the addition of a root node in order to be parsed" (ibid., 48). Zoll views the differences among subsegments to derive from the source of the inserted root node: "In the case of surface dependent features, an existing segment provides the appropriate anchor, while for latent segments a new root node is epenthesised to host the feature" (idem.).

\section{Method}

Following this background, this paper aims to analyse the process of hiatus resolution in Persian in the /e-i/ - and the closely related /e-a/ - environment, within an Optimality-theoretic framework. The data include the set of Persian tetrasyllables which display the aforementioned hiatus in morpheme-boundary positions. However, this choice does not imply that there is anything special about this set of words in terms of their hiatusresolving processes; rather, the reason only being that this study is part of a larger project which examines the phonotactic constraints of tetrasyllables in Persian. The words were extracted from a contemporary Persian dictionary (Moshiri 2009), and sorted in a Microsoft Office Excel worksheet with all their phonological and morphological information subsequently added. A total of 112 words displaying the aforesaid hiatus in morpheme-boundary positions (all in their final syllable) were then identified. The data are referred to in the course of analysis as examples and as supporting evidence for the claims made in the study.

We adopt a constraint-based Optimality-theoretic framework in our analyses (Prince \& Smolensky 2004; McCarthy 2008). The constraints used in the paper are each defined in the relevant sections when first used in the analyses and in the tableaux. 


\section{Analysis and discussion}

In what follows, the cases of hiatus resolution in Persian in the /e-i/ and /e-a/ environments are discussed in turn. For the ease of analysis, the discussions are presented in separate subsections.

\subsection{Hiatus resolution in the /e-i/ environment}

\subsection{1. [?]-epenthesis in adjective-forming derivation}

As already alluded to in the introduction, in adjective-forming derivations, in an /e-i/ environment a glottal stop [?] is inserted to resolve the hiatus. This is in line with the fact that [?] is a highly unmarked epenthetic consonant cross-linguistically. Lombardi (2001b) explains the unmarked behaviour of glottal stop by extending the place markedness hierarchy proposed by Prince and Smolensky (2004) reproduced in (5) to include the pharyngeal place of articulation. In her discussion, "it is assumed that glottal stop has pharyngeal place (McCarthy 1994)" (Lombardi 2002, 4) and the subordinate feature [+glottal]. Lombardi adds pharyngeal place of articulation to the previous hierarchy as the least marked place:

$$
{ }^{*} \mathrm{LAB},{ }^{*} \mathrm{DOR} \gg{ }^{*} \mathrm{COR} \gg{ }^{*} \mathrm{PHAR}
$$

Then, to avoid the false prediction of highly marked pharyngeals like [ $\mathrm{f}]$ in epenthesis, she further assumes that "in the case of pharyngeals it is the ranking $*$ [-glottal $] \gg *[+$ glottal $]$ which makes the true pharyngeals marked." (ibid., 5).

Using the same hierarchy of place markedness given in (13) we can analyse the optimal output for a typical adjective ending in an /e-i/ hiatus. Tableau 1 illustrates the evaluation for the input adjective $/$ setare $^{[j]}-\mathrm{i} /{ }^{5}$ 'starlike'. The other constrains used in the tableau are defined below (McCarthy 2008):

(14) ONSET

Assign one violation mark for every onsetless syllable.

(15) Max

Assign one violation mark for every input segment that does not have an output correspondent. (No deletion)

${ }^{5}$ Following the discussion in the previous section, we assume the subsegment $[\mathrm{f}]$ to be latently present at the end of words ending in /e/ in Modern Persian. We indicate the latent status of this segment by using superscripts ${ }^{[j]}$. 
(16) DEP

Assign one violation mark for every output segment that does not have an input correspondent. (No epenthesis)

Following our discussion in the previous section on considering the final [f] as a subsegment, we also need to introduce a subsegmental faithfulness constraint which encourages the realisation of subsegments in the output. This faithfulness constraint is defined below (Zoll 2001, 60):

(17) Max(subseg)

Assign one violation mark for every subsegment in the input that does not have a correspondent in the output.

However, this constraint should be crucially dominated in Persian to ensure that a subsegmental [f] does not surface unless a higher-ranked constraint forces it (Naderi \& van Oostendorp 2011, 161).

(18) Tableau 1. Evaluation tableau for the input adjective /setare[f]-i/ 'starlike'

\begin{tabular}{|c||c|c|c|c|c|c|c|}
\hline$/$ setare $^{[\mathrm{f}]}$-i/ & ONSET & MAX & $*$ DOR & $*$ COR & ${ }^{* \text { PHAR }}$ & $\begin{array}{c}\text { MAX } \\
\text { (subseg) }\end{array}$ & DEP \\
\hline \hline se.ta.re.Pi & & & & $* * *$ & $*$ & $*$ & $*$ \\
\hline se.ta.re.i & $* !$ & & & $* * *$ & & $*$ & \\
\hline se.ta.re.ji & & & $* !$ & $* * *$ & & & $*$ \\
\hline se.ta.ri & & $* !$ & & $* * *$ & & $*$ & \\
\hline
\end{tabular}

In Tableau 1 above, the undominated constraint ONSET is ranked highest, since in Persian every syllable in phonetic realisation needs to have an obligatory onset. Of the two faithfulness constraints MAX and DEP, MAX is ranked higher since Persian resorts to epenthesis, rather than deletion, to resolve a case of hiatus in the output. The place markedness constraints are ranked in the order given in (13), in between the faithfulness constrains to give us the correct optimal output [se.ta.re.?i]. Finally, the above-introduced faithfulness constraint MAX(subseg) is ranked low enough to ensure that a subsegment [f] never surfaces in the output unless a higherranking constraint forces it. The two low-ranked faithfulness constraints MAX(subseg) and DEP are equally dominated in Persian and there is no direct ranking argument to position one higher than the other (and hence the dotted line).

Tableau 1 can be compared with Tableau 2 below which evaluates the optimal output for the simple noun / setare $^{[f]} /$ 'star' with a latent [f] at 
the end which never gets a chance to surface with this order of conflicting constraints.

(19) Tableau 2. Evaluation tableau for the input noun / setare $^{[\mathrm{f}]} /$ 'star'

\begin{tabular}{|c||c|c|c|c|c|c|c|}
\hline$/$ setare $^{[\mathrm{J}]} /$ & ONSET & MAX & *DOR & *COR & *PHAR & $\begin{array}{c}\text { MAX } \\
\text { (subseg) }\end{array}$ & DEP \\
\hline \hline se.ta.re & & & & $* * *$ & & $*$ & \\
\hline se.ta.re & & & $* !$ & $* * *$ & & & $*$ \\
\hline se.ta.re? & & & & $* * *$ & $* !$ & $*$ & $*$ \\
\hline
\end{tabular}

Thus far in our analysis, we did not have the need to resort to morpheme-specific constraints since the epenthesis of a glottal stop [?] is phonetically justified cross-linguistically and the universal constraints used in the above analyses suffice to give us the correct optimal output in an adjective-forming derivation with /-i/.

\subsection{2. [t]-epenthesis in noun-forming derivation}

An explanation for the epenthesis of $[f]$ is less straightforward, however. We followed Naderi and van Oostendorp (2011) in assuming that the epenthetic $[f]$ is actually a latent segment which surfaces only in specific cases when needed to resolve a hiatus. Naderi and van Oostendorp $(2011,160)$ propose morpheme-specific alignment constraints of the type given below to allow for the latent [f] to be parsed only in relevant morpho-phonemic contexts. What they do not note, however, is the fact that the adjectiviser /-i/ and the nominaliser /-i/ behave differently in terms of whether they trigger this latent $[\mathrm{f}]$ to be parsed in respective derivations. Here, the morpheme-specific constraint covering the derivational suffix /-i / is reproduced below with slight modification to include only a nominaliser $/-\mathrm{i} /$, and not the adjectiviser $/-\mathrm{i} /$.

(20) Align-Right(-inom, base)

Assign one violation mark for every segment intervening between the nominaliser $-i$ and the right edge of the base.

We still need a new faithfulness constraint whose conflict with the subsegmental faithfulness constraint in (17) - i.e., MAx(subseg) - determines whether the subsegment should be realised or not. This faithfulness constraint (Zoll 2001, 66) is defined below: 
(21) Dep(base)

Assign one violation mark for every output base node that does not have an input correspondent.

As already discussed above, MAX(subseg) is crucially dominated in Persian to ensure that a subsegmental [f] never surfaces unless a higher-ranked constraint forces it. Accordingly, the morpheme-specific ALIGN-R(- $i_{\text {nom }}$, base) and the faithfulness constraint DEP(base) should both be ranked higher than Max(subseg) in Persian to give us the optimal output in a nounforming derivation:

\section{Align-R(- $i_{\text {nom }}$, base $), \operatorname{DeP}($ base $) \gg \operatorname{Max}($ subseg $)$}

In Tableau 3, the input noun / divane ${ }^{[\mathrm{f}]}-\mathrm{i} /$ 'insanity' is evaluated based on the ranking of the conflicting constraints defined above:

(23) Tableau 3. Evaluation tableau for the input noun /divane $\mathrm{e}^{[\mathrm{f}]}-\mathrm{i} /$ 'insanity'

\begin{tabular}{|c||c|c|c|c|c|c|}
\hline /divane $^{[\mathrm{J}] \mathrm{i} /}$ & ONSET & MAX & $\begin{array}{c}\text { ALIGN-R } \\
\left(\boldsymbol{i}_{\text {nom }} \text {, base }\right)\end{array}$ & DEP(base) & *DoR & $\begin{array}{c}\text { MAX } \\
\text { (subseg) }\end{array}$ \\
\hline \hline di.va.ne.ji & & & & $*$ & $*$ & \\
\hline di.va.ne.i & $* !$ & & & & & $*$ \\
\hline di.va.ne.?i & & & $* !$ & $*$ & & $*$ \\
\hline di.va.ni & & $* !$ & & & & $*$ \\
\hline
\end{tabular}

Again, Tableau 3 above is comparable with the following tableau which evaluates the adjective form / divane $\mathrm{e}^{[\mathrm{f}]} /$ 'insane'. In Tableau 4, ALIGN$\mathrm{R}\left(-i_{\text {nom }}\right.$, base $)$ constraint becomes inactive since there is no noun-forming derivation. In this case, DeP(base) correctly decides on the optimal output [di.va.ne].

(24) Tableau 4. Evaluation tableau for the input adjective /divane ${ }^{[f]} /$ 'insane'

\begin{tabular}{|c|c|c|c|c|c|c|}
\hline /divane $^{[\mathrm{J}] /}$ & ONSET & MAX & $\begin{array}{c}\text { ALIGN-R } \\
\left(\boldsymbol{i}_{\text {nom }}, \text { base }\right)\end{array}$ & DEP(base) & *DOR & $\begin{array}{c}\text { MAX } \\
\text { (subseg) }\end{array}$ \\
\hline \hline di.va.ne & & & & & & $*$ \\
\hline di.va.nef & & & & $* !$ & $*$ & \\
\hline di.va.ne? & & & & $* !$ & & $*$ \\
\hline
\end{tabular}

In the next section, we shall analyse the occurrence of $[\mathrm{f}]$ as a hiatusresolving consonant in the /e-a/ environment. 


\subsection{Hiatus resolution in the /e- $a /$ environment}

\subsection{1. [t]-epenthesis in plural formation}

Another related morpho-phonemic environment in which [f] emerges is an /e-a/ hiatus, resulting from two types of suffixation defined in (7) and (8) above - i.e., the plural suffixation and the adverbial suffixation. Below are examples of plural suffixation with /-an/ resulting in an /e-a/ hiatus:

(25) Pluraliser /-an/ added to bases ending in /e/

$$
\begin{array}{ll}
\text { /setare/ 'star' (n.) }+/ \text {-an/ } & \rightarrow \text { [setaregan] 'stars' (n.) } \\
\text { /ferefte/ 'angel' (n.) }+/ \text {-an/ } & \rightarrow \text { [fereftegan] 'angels' (n.) } \\
\text { /parande/ 'bird' (n.) }+/ \text {-an/ } & \rightarrow \text { [parandegan] 'birds' (n.) } \\
\text { /divane/ 'insane' (adj.) }+/ \text {-an/ } \rightarrow \text { [divanegan] 'the insane' (n.) }
\end{array}
$$

The same argument made in previous sections about a latent $[\mathrm{f}]$ being present as a subsegment at the end of these words applies here. We need another morpheme-specific constraint to cover this pluraliser suffix and to ensure that the latent $[f]$ emerges in the right context. This constraint is defined below (Naderi \& van Oostendorp 2011, 160):

(26) Align-Right(-an, base)

Assign one violation mark for every segment intervening between the pluraliser -an and the right edge of the base.

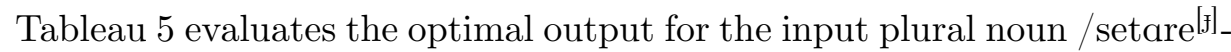
an/ 'stars'. The morpheme-specific constraint in this case is the ALIGNRight(-an, base) constraint since the alignment concerns a plural suffixation.

(27) Tableau 5. Evaluation tableau for the input noun / setare ${ }^{[j]}-a n /$ 'stars'

\begin{tabular}{|c||c|c|c|c|c|c|}
\hline$/$ setare $^{[j]}$-an/ & ONSET & MAX & $\begin{array}{c}\text { ALIGN-R } \\
(\text { an }, \text { base })\end{array}$ & DEP(base) & *DoR & $\begin{array}{c}\text { MAX } \\
\text { (subseg) }\end{array}$ \\
\hline \hline se.ta.re.gan & & & & $*$ & $*$ & \\
\hline se.ta.re.an & $* !$ & & & & & $*$ \\
\hline se.ta.re.Pan & & & $* !$ & $*$ & & $*$ \\
\hline se.ta.ran & & $* !$ & & & & $*$ \\
\hline
\end{tabular}

\subsection{2. [t]-epenthesis in adverb-forming derivation}

The last morpho-phonemic context to be discussed here is an adverbial suffixation resulting in an /e-a/ hiatus. The following examples show the 
adverbialiser /-ane/ suffixed to bases ending in a consonant - /sabur/ 'patient' - and another one ending in /e/ - /batffe/ 'child':

(28) Adverbialiser /-ane/ added to bases ending in a consonant (/sabur/) and in /e/ (/battge/)

/sabur/ 'patient' (adj.) + /-ane/ $\rightarrow$ [saburane] 'patiently' (adv.)

/battfe/ 'child' (n.) + /-ane/ $\rightarrow$ [battfegane] 'childishly' (adv.)

As can be seen, in /batffe-ane/ a root-final latent segment [f] surfaces again to resolve the hiatus - which is realised here as a velar $[\mathrm{g}]$ before the back vowel $[a]$. The last morpheme-specific constraint needed to account for the realisation of the latent [f] - and not any other epenthetic segment, like [?] - in an adverbial suffixation is defined below (Naderi \& van Oostendorp 2011, 160):

(29) Align-Right(-ane, base)

Assign one violation mark for every segment intervening between the adverbialiser -ane and the right edge of the base.

Tableau 6 evaluates the optimal output for the input adverb /batfffe ${ }^{[f]}$ ane/. The morpheme-specific constraint used this time is ALIGn-RIgHT (-ane, base) since the alignment is concerned with an adverbial suffixation with /-ane/.

(30) Tableau 6. Evaluation tableau for the input adverb /batt $\mathrm{fe} \mathrm{e}^{[\mathrm{fj}]}$-ane/ 'childishly'

\begin{tabular}{|c|c|c|c|c|c|c|}
\hline /batft $\int \mathrm{e}^{[\mathrm{f}]}$-ane/ & ONSET & MAX & $\begin{array}{l}\text { ALIGN-R } \\
\text { (ane, base) }\end{array}$ & DEP(base) & *DOR & $\begin{array}{c}\text { MAX } \\
\text { (subseg) }\end{array}$ \\
\hline batf.tfe.ga.ne & & & & * & * & \\
\hline batf.tfe.a.ne & $* !$ & & & & & * \\
\hline batf.tfe.?a.ne & & & $* !$ & * & & * \\
\hline batf.tfa.ne & & $* !$ & & & & * \\
\hline
\end{tabular}

\section{Conclusion}

In this paper, we argued that the insertion of $[f]$ as a hiatus-resolving consonant in Persian is historically driven. We followed Naderi and van Oostendorp (2011) in assuming that the hiatus-resolving [f] is actually a latent segment at the end of bases ending in /e/ - in some words as a relic from the Middle (Pahlavi) Persian and in others as a matter of 
analogy -, surfacing only in certain morpho-phonemic contexts. Phonetically, [f]-epenthesis is limited to the /e-i/ and /e-a/ environments. Morphologically, it is limited to the three types of suffixation sketched in (6) to (8); namely, noun-forming derivation with /-i/, plural formation with /-an/, and adverb-forming derivation with /-ane/. Within an Optimalitytheoretic framework, we tried to achieve a unified explanation and a set order of constraints active for hiatus resolution in the /e-i/ and /e-a/ environments.

The overall ranking of the constraints discussed throughout this paper and used in the tableaux is given in (31):

(31) Onset $\gg$ Max $\gg$ Align-R(- $i_{\text {nom }}$, base), Align-R(-an, base), Align-R(-ane, base), DeP(base) $\gg *$ LAB, ${ }^{*}$ Dor $\gg *$ Cor $\gg *$ Phar $\gg$ MAx(subseg), DeP

It was argued that the two hiatus-resolving consonants realised in an $/ \mathrm{e}-\mathrm{i} /$ environment in /-i/-suffixation - i.e., the phonetically-driven [?] and the historically-driven $[\mathrm{f}]$ - are in fact in complementary distribution depending on the grammatical class of the output word. The hiatus-resolving $[\mathrm{f}]$ emerges with the nominaliser /-i/ in a noun-forming derivation, while [?] is epenthesised in an adjective-forming derivation with the adjectiviser $/-\mathrm{i} /$. Out of the 112 Persian tetrasyllables in our data set which displayed the /e-i/ hiatus in morpheme-boundary positions (all in their final syllable), 106 words were nouns ending in an [_efi] sequence in their phonetic realisations, and the rest were adjectives all ending in an [_e?i] sequence. The low number of adjectives relative to nouns can be attributed to the fact that adjective-forming via the adjectiviser /-i/ is a highly regular process in Persian and the adjective forms made this way do not generally need to have separate entries in a dictionary. Nonetheless, what is evident is that the two hiatus-resolving consonants are in complementary distribution depending on whether the output word is a noun or an adjective.

The very few - non-tetrasyllabic, and hence not included in our data

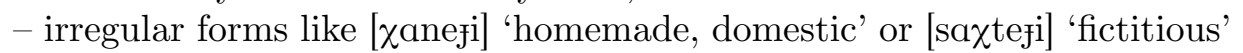
count as exceptions to the generalisation made above and the overall ranking given in (31), since they resolve in an [_efi] sequence and yet they function as adjectives in contemporary Persian; ${ }^{6}$ as in the phrases [Gazaje $\chi$ aneji] 'homemade food' or [hovijjate sa $\chi$ teji] 'fictitious identity'. However, in the data under focus in our study - i.e., the Persian tetra-

${ }^{6}$ It can be argued that [sa $\mathrm{xte}$ i] is both a noun and an adjective in contemporary Persian. As a noun, it means 'the state of being structured; structuredness'. However, in everyday language it is mostly used as an adjective meaning 'fictitious'. 
syllables - all the instances having an /e-i/ hiatus indicate a unified pattern in their phonetic realisations so that the words ending in an [_efi] sequence represented nouns and the ones ending in [_e?i] were all adjectives.

\section{References}

Bijankhan, Mahmood. 2005. Vājshenāsi: Nazariye-ye behinegi [Phonology: Optimality theory]. Tehran: Samt.

Kambuziya, Aliyeh K. Z. 2007. Vājshenāsi: Ruykardhā-ye ghā'ede-bonyād [Phonology: Rule-based approaches]. Tehran: Samt.

Kambuziya, Aliyeh K. Z., Amir Ghorbanpour and Nader Mahdipour. 2017. Vowel shortening in Persian: A phonological analysis. Poznań Studies in Contemporary Linguistics 53. 373-397.

Kenstowicz, Michael. 1994. Phonology in generative grammar. Cambridge, MA \& Oxford: Blackwell.

Lombardi, Linda (ed.). 2001a. Segmental phonology in Optimality Theory. Cambridge: Cambridge University Press.

Lombardi, Linda. 2001b. Why place and voice are different: Constraint-specific alternations in Optimality Theory. In Lombardi (2001a, 13-45).

Lombardi, Linda. 2002. Coronal epenthesis and markedness. Phonology 19. 219-251.

McCarthy, John J. 1994. The phonetics and phonology of Semitic pharyngeals. In P. A. Keating (ed.) Phonological structure and phonetic form: Papers in laboratory phonology III. Cambridge: Cambridge University Press. 191-233.

McCarthy, John J. 2008. Doing Optimality theory: Applying theory to data. Malden, MA \& Oxford: Blackwell.

Moshiri, Mahshid. 2009. Farhang-e zabān-e Fārsi [Persian dictionary (alphabetical-analogical)] (5th ed.). Tehran: Soroush.

Naderi, Navid and Marc van Oostendorp. 2011. Reducing the number of Farsi epenthetic consonants. In A. Korn, G. Haig, S. Karimi and P. Samvelian (eds.) Topics in Iranian linguistics. Wiesbaden: Reichert. 153-166.

Prince, Alan and Paul Smolensky. 2004. Optimality Theory: Constraint interaction in Generative Grammar. Malden, MA \& Oxford: Blackwell.

Sadeghi, Ali Ashraf. 2002. Elteghā-ye mosavvet-hā va mas'ale-ye sāmet-e miyānji [Vowel hiatus and the issue of the epenthetic consonant]. In A. A. Sadeghi (ed.) Masā'el-e tārikhi-ye zabān-e Fārsi [Historical issues of Persian]. Tehran: Sokhan. 25-50.

Zoll, Cheryl C. 2001. Constraints and representation in subsegmental phonology. In Lombardi (2001a, 46-78). 